\title{
LOGIKA FUZZY MENENTUKAN JUMLAH PRODUKSI BERDASARKAN PERSEDIAAN DAN JUMLAH PERMINTAAN
}

\author{
Yusli Yenni', Muhammad Irsan ${ }^{2}$ \\ ${ }^{12}$ Fakultas Teknik Universitas Putera Batam \\ email : yusliany10@gmail.com
}

Submitted: 16-03-2017, Reviewed: 17 -03- 2017, Accepted 18-03-2017

http://dx.doi.org/10.22202/jei.2017.v3i2.2247

\begin{abstract}
The complicated to determine total of product will be production with stock, make the process of decision be slowly. The purpose of this research for implementated fuzzy logic Mamdani method for determine the total of production basis on the total of stock and the total of request at OSI Electronics Batam, Corp and description of accuracy level. The first process analyze the corporation data with total 12 data start from January - December 2015. The data will be processed using MATLAB application with first step is fuzzyfication defene the membership function. There are 2 information as fuzzy input request and stock and will be processed using triangle and trapezoid membership function. Next step is implicated all rules and this research using 26 rules, rule compositions and the last step is defuzzyfication using bisector method. The accuracy using fuzzy logic that was built were $91,67 \%$ and error 9,37\%.
\end{abstract}

Keyword: Production, Request, Stock, Fuzzy Logic, Mamdani Method,

\begin{abstract}
Abstrak
Sulitnya menentukan ketentuan total jumlah barang yang akan diproduksi berdasarkan persediaan barang membuat proses keputusan menjadi lambat. Penelitian ini bertujuan untuk menerapkan logika fuzzy dengan metode mamdani untuk menentukan jumlah produksi berdasarkan jumlah persediaan dan jumlah permintaan pada PT OSI Electronics Batam dan mendeskripsikan tingkat keakuratannya. Proses yang dilakukan dengan menganalisa data perusahaan dengan jumlah data sebanyak 12 mulai dari bulan januari 2015 sampai bulan desember 2015. Data yang didapat selanjutnya diolah menggunakan MATLAB dengan tahap awal fuzzifikasi mendefenisikan fungsi keanggotaan. Terdapat 2 informasi sebagai input fuzzy yaitu persediaan dan permintaan yang diolah dengan fungsi keanggotaan trapesium dan segitiga. Selanjutnya mengimplikasikan seluruh aturan dengan jumlah aturan sebanyak 26 rules, komposisi aturan dan langkah terakhir adalah defuzzifikasi menggunakan metode bisektor. Model fuzzy yang telah dibangun akan dilakukan pengujian model dengan cara menentukan tingkat keakuratan dan error dari model tersebut. Dengan hasil 91,67\% dengan tingkat error sebesar 9,37\%.
\end{abstract}

Kata kunci: Produksi, Permintaan, Persediaan, Logika Fuzzy, Mamdani

\section{PENDAHULUAN}

PT OSI Electronics merupakan salah satu perusahaan manufaktur elektronik yang berkembang saat ini, PT OSI yang memiliki pengalaman di bidang manufaktur operasi Liquid
Crystal Display, modul $L C D$ dan Electronics Store Labeling (ESL) sistem. PT OSI Electronics memiliki lima gedung di kawasan Cammo Industrial Park, dengan gedung utamanya berada di Cammo Industrial Park blok F No 3A Batam center. 
Proses produksi merupakan hal yang paling utama pada setiap perusahaan karena, produksi merupakan aktivitas yang memberikan suatu nilai tambah pada bahan suatu produk yang memiliki nilai lebih agar bermanfaat bagi perusahaan atau pengguna lainnya. Persediaan (inventory) menjadikan salah satu kegiatan utama dalam sistem produksi dengan tujuan merencanakan dan mengendalikan persediaan produksi untuk menghasilkan output produksi sesuainya dengan suatu permintaan (purchases Order).

Dalam perusahaan PT OSI tersebut mempunyai suatu kendala atau permasalahan yang sering terjadi dalam suatu proses produksi yaitu persediaan yang diproduksi. Yaitu sulitnya menentukan jumlah produksi berdasarkan persediaan dari jumlah permintaan pada pelanggan. Jumlah produksi dalam seharinya tidak tetap, dapat berubahubah sesuai dengan persediaan barang yang dimiliki oleh perusahaan tersebut terkadang lambat datangnya material yang hendak dirakit.

Logika fuzzy dianggap mampu untuk memetakan suatu ruang input ke dalam suatu ruang output. Logika fuzzy diyakini sangat fleksibel dan memiliki nilai toleransi terhadap data yang ada. Dengan berdasarkan logika fuzzy, akan dihasilkan suatu model dari sistem yang mampu memperkirakan jumlah produksi dengan logika fuzzy antara lain jumlah permintaan dan jumlah persediaan barang.

\section{Kecerdasan Buatan (Artificial Intelligence)}

AI mencakup bidang yang cukup besar. Mulai dari yang paling umum hingga yang khusus. Dari learning atau preception hingga pada permainan catur, pembuktian teori matematika, menulis puisi, mengemudikan mobil dan melakukan diagnosis penyakit. AI relevan dengan berbagai macam task kecerdasan, AI merupakan sebuah ilmu yang universal.

Menurut Budiharto dan Suhartono (2014: 3), kata intelligence berasal dari bahasa latin intelligo yang berarti 'saya paham'. Jadi, dasar dari intelligence adalah kemampuan memahami dan melakukan aksi. Menurut Budiharto dan Suhartono (2014: 3), kata intelligence berasal dari bahasa latin intelligo yang berarti 'saya paham'. Jadi, dasar dari intelligence adalah kemampuan memahami dan melakukan aksi.

\section{Logika Fuzzy}

Menurut Budhiharto dan Suhartono (2014: 149) logika fuzzy pertama kali di perkenalkan oleh Lotfi A. Zadeh, seorang profesor dari university of California. Logika fuzzy memiliki derajat keanggotaan dalam rentang 0 (nol) hingga 1 (satu), berbeda dengan logika digital atau diskrit yang hanya memiliki dua nilai yaitu 1 (satu) dan 0 (nol). Logika fuzzy di gunakan untuk menerjemahkan suatu besaran yang diekspresikan menggunakan bahasa (linguistic).

Tidak seperti logika boolean yang memiliki 2 nilai, logika fuzzy terdiri dari banyak nilai. Logika fuzzy menangani derajat keanggotaan dan derajat kebenaran. Logika fuzzy menggunakan nilai berkelanjutan nilai berkelanjutan antara 0 (sepenuhnya salah) dan 1 (sepenuhnya benar). Tidak hanya hitam dan putih, logika fuzzy mencakup sprektum warna, menandakan bahwa elemen-elemen bisa sebagian benar dan sebagian salah pada waktu yang sama.

Menurut Budiharto dan Suhartotno (2014 :152) logika fuzzy memiliki banyak kelebihan, yaitu dapat mengontrol sistem yang kompleks, non-linier, dan sistem yang sulit direpresentasikan secara sistematis. Berikut beberapa alasan menggunakan logika fuzzy:

1. Konsep logika fuzzy mudah dimengerti. Konsep matematis yang mendasari penalaran fuzzy sangat sederhana dan mudah dimengerti.

2. Logika fuzzy mampu memodelkan fungsi-fungsi non-linier yang sangat kompleks.

3. Logika fuzzy didasarkan pada bahasa alami. 
4. Logika fuzzy sangat fleksibel.

5. Logika fuzzy dapat bekerja sama dengan teknik-teknik kendali secara konvensional.

\section{Logika Fuzzy metode Mamdani}

Menurut Kusumadewi (2013: 37) metode Mamdani sering disebut dengan metode Max-Min. Metode ini diperkenalkan oleh Ebrahim Mamdani pada tahun 1975. Untuk mendapatkan output, diperlukan 4 tahapan :

1. Pembentukan himpunan fuzzy

Pada metode mamdani, baik variabel input atau variabel output dibagi menjadi satu atau lebih himpunan fuzzy.

2. Aplikasi fungsi implikasi

Pada metode mamdani, fungsi implikasi yang digunakan adalah Min.

3. Komposisi area

Apabila sistem terdiri dari beberapa aturan, maka inferensi diperoleh dari kumpulan dan korelasi antar aturan. Ada 3 metode yang digunakan dalam melakukan inferensi sistem fuzzy, yaitu: Max, Additive dan Probabilistik OR.

4. Penegasan (Defuzzyfikasi)

Input dari proses defuzzy adalah suatu himpunan fuzzy yang di peroleh dari komposisi aturan aturan fuzzy, sedangkan output yang di hasilkan merupakan suatu bilangan pada domain himpunan fuzzy tersebut. Sehingga jika diberikan suatu himpunan fuzzy dalam range tertentu, maka harus dapat diambil suatu nilai crisp tertentu sebagai output

\section{Variabel}

Adapun variabel-variabel yang digunakan dalam penelitian ini adalah:

\section{a). Persediaan (inventory)}

Persediaan adalah sumber daya yang menganggur (idle resource) yang menunggu proses lebih lanjut. Yang dimaksud dengan proses lebih lanjut tersebut adalah berupa kegiatan produksi pada sistem manufaktur, kegiatan pemasaran pada sistem distribusi ataupun kegiatan konsumsi pangan pada sistem rumah tangga. b). Permintaan

Permintaan adalah banyaknya jumlah barang yang diminta pada suatu pasar tertentu dengan tingkat harga tertentu pada tingkat pendapatan tertentu.

\section{Tools}

Dalam penelitian ini menggunakan tools yait program matlab 6.1. MATLAB merupakan perangkat lunak yang cocok dipakai sebagai alat komputai yang melibatkan penggunaan matriks dan vektor. Fungsi-fungsi dalam toolbox MATLAB dibuat untuk memudahkan perhitungan tersebut, (Siang, 2009: 151).

MATLAB merupakan perangkat lunak yang cocok dipakai sebagai alat komputai yang melibatkan penggunaan matriks dan vektor. Fungsi-fungsi dalam toolbox MATLAB dibuat untuk memudahkan perhitungan tersebut, (Siang, 2009: 151). MATLAB dapat dengan mudah dipakai untuk menyelesaikan permasalahan sistem persamaan linear, program linear, dengan simpleks, sehingga sistem yang kompleks seperti peramalan runtunan waktu (time series), pengolahan citra, dan lainnya. (Siang, 2009: 151).

\section{Desain Penelitian}

Adapun desain penelitiannya adalah sebagai berikut:

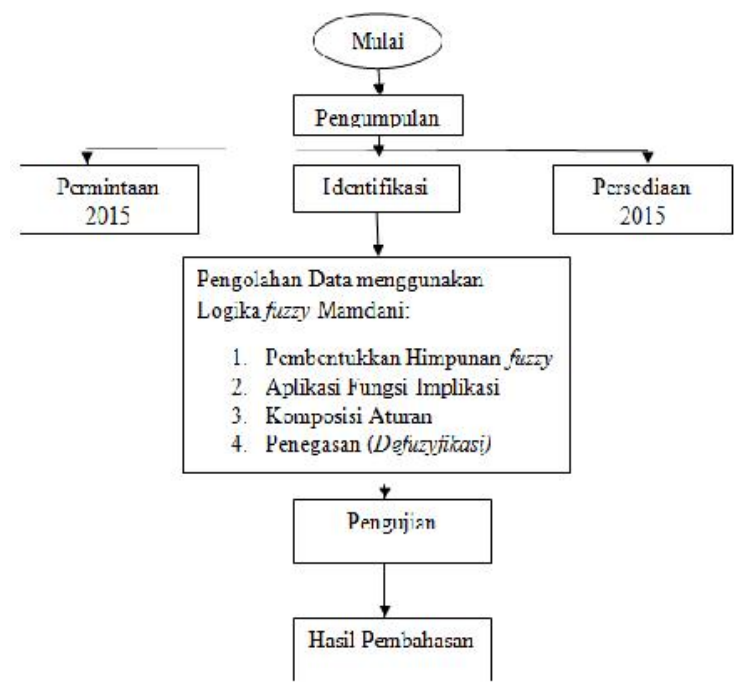


Sumber: Penelitian Terdahulu

\section{Gambar 1: Desain Penelitian}

\section{Teknik Pengumpulan Data}

Disetiap penelitian pasti ada teknik utama yang digunakan peneliti untuk menggali data penelitian. Musfiqon (2012: 116), teknik utama ini biasanya digunakan untuk menggali data primer dalam penelitian.

Sedangkan data sekunder digali menggunakan teknik lain yang juga diterapkan dalam penelitian.

\section{1) Teknik Wawancara}

Yaitu teknik pengumpulan data dimana peneliti mencari data tentang pemikiran, konsep atau pengalaman mendalam dari informan. Penggunaan teknik wawancara dalam penelitian dimaksudkan agar peneliti dapat mengkontruksi pemikiran, kejadian, kegiatan, motivasi, persepsi, kepedulian, pengalaman, serta opini mendalam tentang masalah penelitian.

\section{2) Teknik Observasi}

Observasi adalah kegiatan pengumpulan data melalui pengamatan atas gejala, fenomena dan fakta empiris yang terkait dengan masalah penelitian.

\section{3) Teknik Dokumentasi}

Teknik dokumentasi digunakan untuk memperoleh data sekunder berupa kumpulan data dan fakta yang tersimpan dalam bentuk teks atau artefak.

\section{Metode Analisis Data}

Dalam menentukan jumlah produksi berdasarkan jumlah persediaan dan jumlah permintaan pada PT. OSI Electronics Batam dengan menggunakan logika kabur atau logika fuzzy dengan metode Mamdani menggunakan bantuan aplikasi atau software Matlab. Adapun analisis data yang digunakan penulis dalam melakukan penelitian ini adalah sebagai berikut:

1. Mengumpulkan data-data permintaan pada setiap bulannya di tahun 2015 .
2. Mengumpulkan data persediaan pada setiap bulannya di tahun 2015 .

3. Menentukan himpunan variabel fuzzy input.

4. Menentukan himpunan variabel fuzzy output.

5. Membentuk sebuah fungsi implikasi

6. Membentuk komposisi aturan.

7. Melakukan defuzzifikasi.

8. Pengujian data.

\section{Analisa Data}

Data yang dikumpulkan Penelitian data permintaan pada tahun 2015 dan data persediaan pada tahun 2015. Adapun datadata yang di dapatkan penulis adalah sebagai berikut:

Tabel 1. Data Permintaan dan Persediaan pada tahun 2015

\begin{tabular}{|l|l|l|l|l|}
\hline $\begin{array}{l}\text { N } \\
\text { B }\end{array}$ & Bulan & $\begin{array}{c}\text { Data } \\
\text { Permint } \\
\text { aan }\end{array}$ & $\begin{array}{c}\text { Data } \\
\text { Persedi } \\
\text { aan }\end{array}$ & $\begin{array}{c}\text { Keteran } \\
\text { gan }\end{array}$ \\
\hline 1 & $\begin{array}{l}\text { Januari } \\
2015\end{array}$ & $\mathbf{8 0 . 3 7 0}$ & $\mathbf{1 9 2 . 0 5 0}$ & Turun \\
\hline 2 & $\begin{array}{l}\text { Februa } \\
\text { ri } 2015\end{array}$ & $\mathbf{7 5 . 9 9 4}$ & $\mathbf{6 4 . 8 7 4}$ & Turun \\
\hline 3 & $\begin{array}{l}\text { Maret } \\
2015\end{array}$ & $\mathbf{1 0 6 . 4 3 8}$ & $\mathbf{9 2 . 2 6 9}$ & Sedang \\
\hline 4 & $\begin{array}{l}\text { April } \\
2015\end{array}$ & $\mathbf{1 5 9 . 4 9 6}$ & $\mathbf{1 1 0 . 5 5 1}$ & Naik \\
\hline 5 & $\begin{array}{l}\text { Mei } \\
2015\end{array}$ & $\mathbf{1 6 8 . 5 8 9}$ & $\mathbf{1 5 9 . 2 1 4}$ & Naik \\
\hline 6 & $\begin{array}{l}\text { Juni } \\
2015\end{array}$ & $\mathbf{1 9 9 . 1 9 4}$ & $\mathbf{1 2 8 . 6 2 4}$ & Sedang \\
\hline 7 & $\begin{array}{l}\text { Juli } \\
2015\end{array}$ & $\mathbf{1 4 4 . 8 2 0}$ & $\mathbf{1 7 3 . 4 1 0}$ & Naik \\
\hline 8 & $\begin{array}{l}\text { Agustu } \\
\text { s 2015 }\end{array}$ & $\mathbf{1 0 3 . 1 3 0}$ & $\mathbf{1 6 2 . 8 6 1}$ & Sedang \\
\hline 9 & $\begin{array}{l}\text { Septem } \\
\text { ber } \\
2015\end{array}$ & $\mathbf{1 5 8 . 0 0 6}$ & $\mathbf{1 3 6 . 7 6 5}$ & Naik \\
\hline 10 & $\begin{array}{l}\text { Oktobe } \\
\text { r 2015 }\end{array}$ & $\mathbf{1 6 1 . 5 9 0}$ & $\mathbf{1 1 6 . 9 1 1}$ & Naik \\
\hline 11 & $\begin{array}{l}\text { Novem } \\
\text { ber } \\
2015\end{array}$ & $\mathbf{5 6 . 0 2 4}$ & $\mathbf{6 0 . 0 9 1}$ & Turun \\
\hline
\end{tabular}




\begin{tabular}{|l|l|l|l|l|}
\hline 12 & $\begin{array}{l}\text { Desem } \\
\text { ber } \\
2015\end{array}$ & $\mathbf{1 4 8 . 1 0 1}$ & $\mathbf{3 2 . 3 8 9}$ & Turun \\
\hline
\end{tabular}

\begin{tabular}{|c|c|c|}
\hline Turun & {$[80$} & {$[80100$} \\
& $120]$ & $120]$ \\
\hline $\begin{array}{c}\text { SangatTur } \\
\text { un }\end{array}$ & {$[56$} & {$[566789$} \\
$100]$ & $100]$ \\
\hline
\end{tabular}

Sumber: Data Olahan Penelitian 2015

\section{Analisa Aliran Fuzzy}

Dalam penelitian ini terdapat 3 variabel, yaitu: 2 variabel input, permintaan dan persediaan. Sedangangkan 1 variabel output, yaitu: produksi. Variabel permintaan memililki 5 nilai linguistik, yaitu sangat turun, turun, sedang, naik, sangat naik. Sedangkan veriabel input persediaan memiliki nilai linguistik yaitu sangat sedikit, sedikit, sedang, banyak dan sangat banyak, dan variabel outputnya memiliki nilai linguistiknya yaitu berkurang sedang dan naik, hal ini dapat dilihat pada gambar sebagai berikut

Tabel 2. Himpunan Fuzzy

\begin{tabular}{|c|c|c|}
\hline \multirow{2}{*}{ Fungsi } & $\begin{array}{c}\text { Nama } \\
\text { Vareabel }\end{array}$ & $\begin{array}{c}\text { Semesta } \\
\text { Pembicaraan }\end{array}$ \\
\hline \multirow{2}{*}{ Input } & Permintaan & {$\left[\begin{array}{ll}56 & 200\end{array}\right]$} \\
\cline { 2 - 3 } & Persediaan & {$\left[\begin{array}{ll}32 & 300\end{array}\right]$} \\
\hline \multirow{2}{*}{ Output } & Produksi & {$\left[\begin{array}{ll}1 & 100\end{array}\right]$} \\
\hline
\end{tabular}

Sumber: Data Olahan Penelitian 2015

\section{Fungsi derajat keanggotan Variabel input Permintaan}

Variabel permintaan terdiri dari 5 himpunan fuzzy, yang terdiri dari (SangatTurun Turun Sedang Naik dan SangatNaik). Berikut ini merupakan variabel Nilai yang di definisikan pada tabel dibawah ini:

Tabel 3 Variabel dan himpunan fuzzy Variabel Permintaan

\begin{tabular}{|c|c|c|c|}
\hline Variabel & $\begin{array}{c}\text { Himpuna } \\
\text { n Fuzzy }\end{array}$ & $\begin{array}{c}\text { Domai } \\
\text { n }\end{array}$ & $\begin{array}{c}\text { Paramet } \\
\text { er }\end{array}$ \\
\hline \multirow{3}{*}{$\begin{array}{c}\text { Perminta } \\
\text { an }\end{array}$} & $\begin{array}{c}\text { SangatNai } \\
\text { k }\end{array}$ & {$[160$} & {$[160170$} \\
\cline { 2 - 4 } & Naik & {$[140]$} & $190200]$ \\
\cline { 2 - 4 } & & $180]$ & {$[140160$} \\
& \multirow{2}{*}{ Sedang } & {$[100$} & {$[100130$} \\
\cline { 2 - 4 } & & $160]$ & $160]$ \\
\cline { 2 - 4 } & & &
\end{tabular}

Berdasarkan tabel diatas pada variabel permintaan mempunyai semesta pembicaraan [56 100] dan himpunan fuzzy nya yaitu: SangatNaik, Naik, Sedang, Turun dan SangatTurun dengan mempunyai parameter pada himpunan SangatNaik [160 170190 200], Naik [140 160 180], Sedang [100 130 160], Turun [80 100 120] dan SangatTurun [56 6789 100].

\section{Fungsi derajat keanggotaan Variabel input Persediaan}

Fungsi keanggotaan untuk variabel input untuk persediaan adalah sebagai berikut:

Tabel 4 variabel dan himpunan fuzzy Variabel Persediaan

\begin{tabular}{|c|c|c|c|}
\hline $\begin{array}{c}\text { Variabe } \\
1\end{array}$ & $\begin{array}{c}\text { Himpunan } \\
\text { Fuzzy }\end{array}$ & $\begin{array}{c}\text { Domai } \\
n\end{array}$ & $\begin{array}{c}\text { Paramet } \\
\text { er }\end{array}$ \\
\hline \multirow{10}{*}{$\begin{array}{c}\text { Persedia } \\
\text { an }\end{array}$} & SangatBany & {$[140$} & {$\left[\begin{array}{lll}140 & 155\end{array}\right.$} \\
\hline & ak & 200] & $185200]$ \\
\hline & \multirow{2}{*}{ Banyak } & {$[120$} & {$\left[\begin{array}{lll}120 & 140\end{array}\right.$} \\
\hline & & $160]$ & $160]$ \\
\hline & \multirow{2}{*}{ Sedang } & {$[80$} & {$\left[\begin{array}{lll}80 & 110\end{array}\right.$} \\
\hline & & 140] & 140] \\
\hline & \multirow{2}{*}{ Sedikit } & {$[60$} & {$\left[\begin{array}{ll}60 & 80\end{array}\right.$} \\
\hline & & 100] & $100]$ \\
\hline & SangatSedi & {$[32$} & {$\left[\begin{array}{lll}32 & 44 & 68\end{array}\right.$} \\
\hline & kit & 80] & 80] \\
\hline
\end{tabular}

Sumber: Data Olahan 2015

Berdasarkan tabel diatas pada variabel persediaan mempunyai beberapa himpunan fuzzy yaitu SangatBanyak, Banyak, Sedang, Sedikit dan SangatSedikit dengan mempunyai parameter pada himpunan SangatBanyak [140 155185 200], Banyak [120 140 160] Sedang [80 110 140], Sedikit [60 80 100] dan SangatSedikit [ $\left[\begin{array}{lll}32 & 44 & 68\end{array}\right.$ $80]$.

\section{Fungsi derajat keanggotaan Variabel Output Produksi}


Variabel produksi ini terdiri dari 3 himpunan, yaitu Turun, Sedang Dan Naik, penjelasannya menggunakan tabel adalah sebagai berikut:

\section{Tabel 5 variabel dan himpunan fuzzy Variabel output Produksi}

\begin{tabular}{|c|c|c|c|}
\hline $\begin{array}{c}\text { Variabe } \\
1\end{array}$ & $\begin{array}{c}\text { Himpuna } \\
\text { n Fuzzy }\end{array}$ & $\begin{array}{c}\text { Domai } \\
\mathbf{n}\end{array}$ & $\begin{array}{c}\text { Paramete } \\
\mathbf{r}\end{array}$ \\
\hline \multirow{3}{*}{$\begin{array}{c}\text { Produks } \\
\text { i }\end{array}$} & Naik & {$\left[\begin{array}{ll}0 & 50\end{array}\right]$} & {$\left[\begin{array}{lll}0 & 25 & 50\end{array}\right]$} \\
\hline & Sedang & {$\left[\begin{array}{ll}25 & 75\end{array}\right]$} & {$\left[\begin{array}{llll}25 & 50 & 75\end{array}\right]$} \\
\hline & Turun & $\begin{array}{c}{[50} \\
100]\end{array}$ & $\begin{array}{c}{[5075} \\
100]\end{array}$ \\
\hline
\end{tabular}

\section{Sumber: Data Olahan 2015}

Berdasarkan tabel diatas pada variabel output produksi mempunyai beberapa himpunan fuzzy yaitu Turun, Sedang, dan Naik. Adapaun setiap himpunan variabelnya mempunya nilai parameter yaitu pada humpunan fuzzy "Turun" dengan domain [0 50] dan memiliki parameter [0 25 50], untuk himpunan "Sedang" dengan domain [25 75] dan memiliki parameter [25 50 75], dan terakhir himpunan "Naik" dengan domain [50 100] dan parameter [50 75 100].

[R1]: IF (Permintaan iis Sangat Turun) and (Persediaan is Sangat Sedikit) THEN (Produksi is Turun).

[R2]: IF (Permintaan is Sangat Turun) and (Persediaan is Sedang) THEN (Produksi isTurun)

[R3] IF (Permintaan is Sangat Turun) and (Persediaan is Sangat Banyak) THEN (Produksi is Turun)

[R4] IF (Permintaan is Sangat Turun) and (Persediaan is Sedikit) THEN (Produksi is Sedang)

[R5] IF (Permintaan is Sangat Turun) and (Persediaan is Banyak) THEN (Produksi is Turun)

[R6] IF (Permintaan is Sedang) and
(Persediaan is Sangat sedikit) THEN (Produksi is Turun)
[R7] IF (Permintaan is Sedang)

and

(Persediaan is Sedang) THEN (Produksi is

Sedang)

[R8] IF (Permintaan is Sedang) and

(Persediaan is Sangat banyak) THEN (Produksi is Sedang)

[R9] IF (Permintaan is Sedang) and

(Persediaan is Sedikit) THEN (Produksi is Turun)

[R10] IF (Permintaan is Sedang) and (Persediaan is Banyak) THEN (Produksi is Sedang)

[R11] IF (Permintaan is Sangat naik) and (Persediaan is Sangat sedikit) THEN (Produksi is turun)

[R12] IF (Permintaan is Sangat naik) and (Persediaan is Sedang) THEN (Produksi is Naik)

[R13] IF (Permintaan is Sangat naik) and (Persediaan is Sangat banyak) THEN (Produksi is Naik)

[R14] IF (Permintaan is Sangat naik) and (Persediaan is Sedikit) THEN (Produksi is Sedang)

[R15] IF (Permintaan is Sangat naik) and (Persediaan is Banyak) THEN (Produksi is Naik)

[R16] IF (Permintaan is Turun) and (Persediaan is Sangat sedikit) THEN (Produksi isturun)

[R17] IF (Permintaan is Turun) and (Persediaan is Sedang) THEN (Produksi is Turun)

[R18] IF (Permintaan is Turun) and (Persediaan is Sangat banyak) THEN (Produksi is sedang)

[R19] IF (Permintaan is Turun) and (Persediaan is Sedikit) THEN (Produksi is Turun)

[R20] IF (Permintaan is Turun) and (Persediaan is Banyak) THEN (Produksi is Turun)

[R21] IF (Permintaan is Naik) and (Persediaan is Sangat sedikit) THEN (Produksi is Turun)

[R22] IF (Permintaan is Naik) and (Persediaan is Sedang) THEN (Produksi is Naik) 
Aturan fuzzy

[R23] IF (Permintaan is Naik) and (Persediaan is Sangat banyak) THEN (Produksi is Naik)

[R24] IF (Permintaan is Naik) and (Persediaan is Sedikit) THEN (Produksi is Turun)

[R25] IF (Permintaan is Naik) and (Persediaan is Sedikit) THEN (Produksi is Sedang)

[R26] IF (Permintaan is Naik) and (Persediaan is Banyak) THEN (Produksi is Naik)

\section{Uji Sistem}

Berikut ini akan menampilkan hasil dengan menggunakan software matlab 6.1 sebagai berikut:

Implementasi variabel permintaan

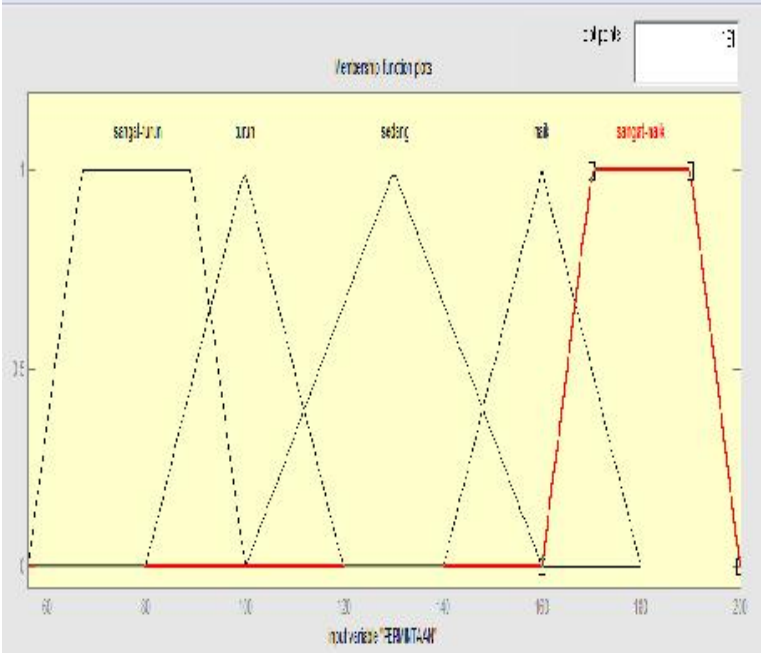

Sumber: data olahan penelitian

Gambar2. himpunan fuzzy SangatNaik

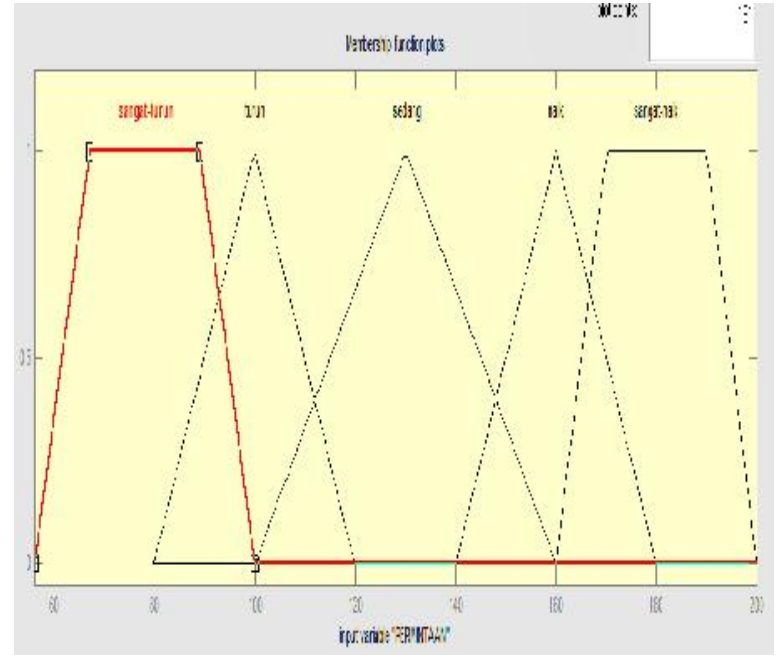

Sumber: data olahan penelitian

Gambar 3. himpunan fuzzy SangatTurun

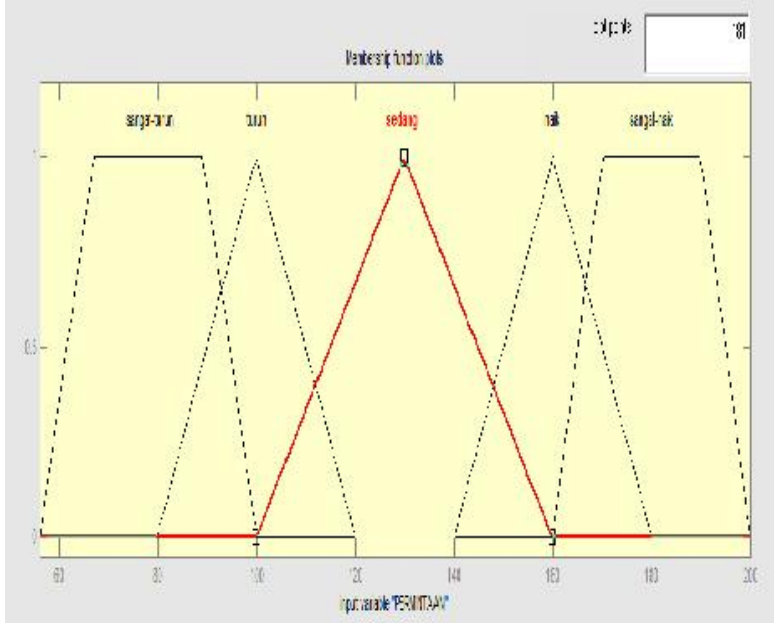

Sumber: data olahan penelitian Gambar 4. himpunan fuzzy SangatSedang

Implementasi variabel Persediaan 


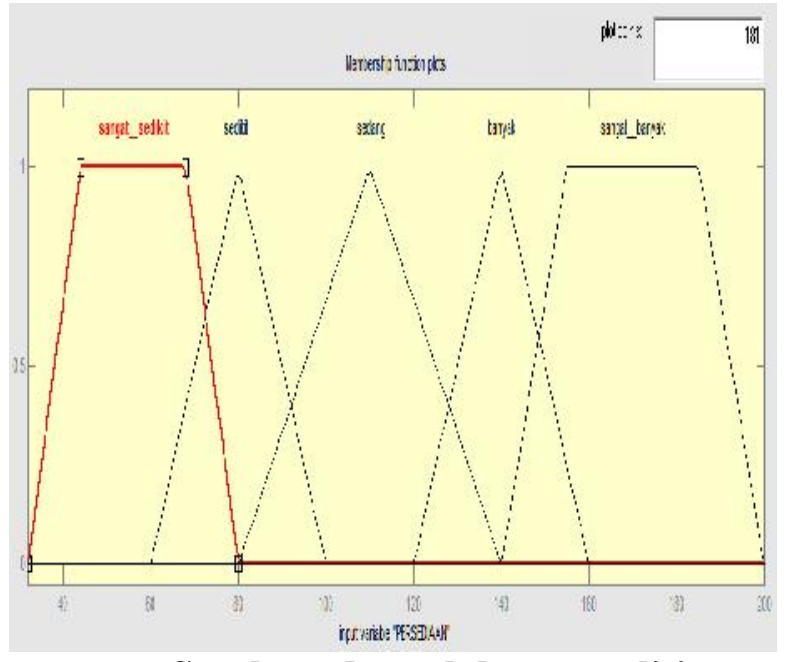

Sumber: data olahan penelitian

Gambar 5. himpunan fuzzy SangatSedang

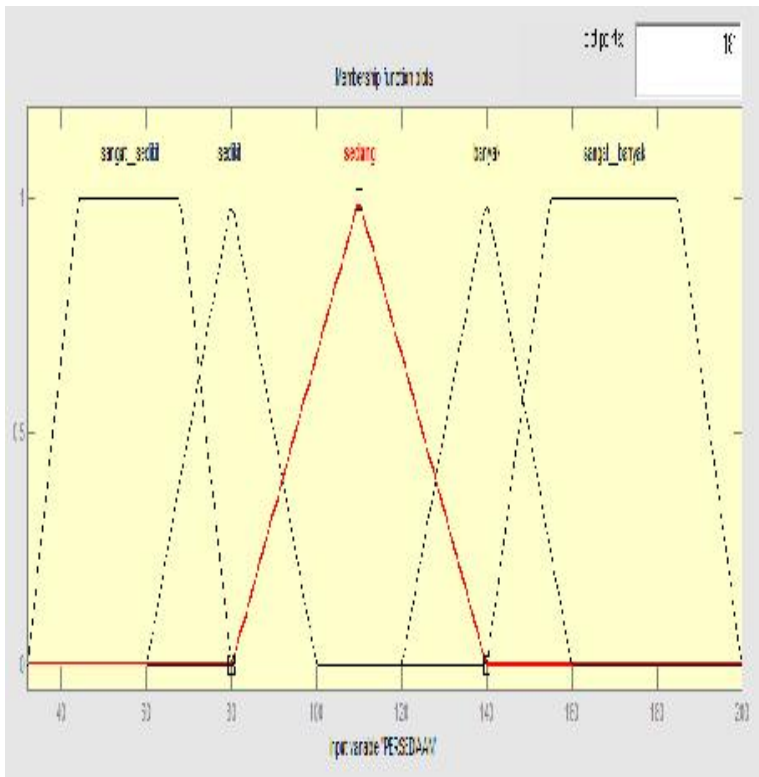

Sumber: data olahan penelitian

Gambar 6. himpunan fuzzy SangatSedang

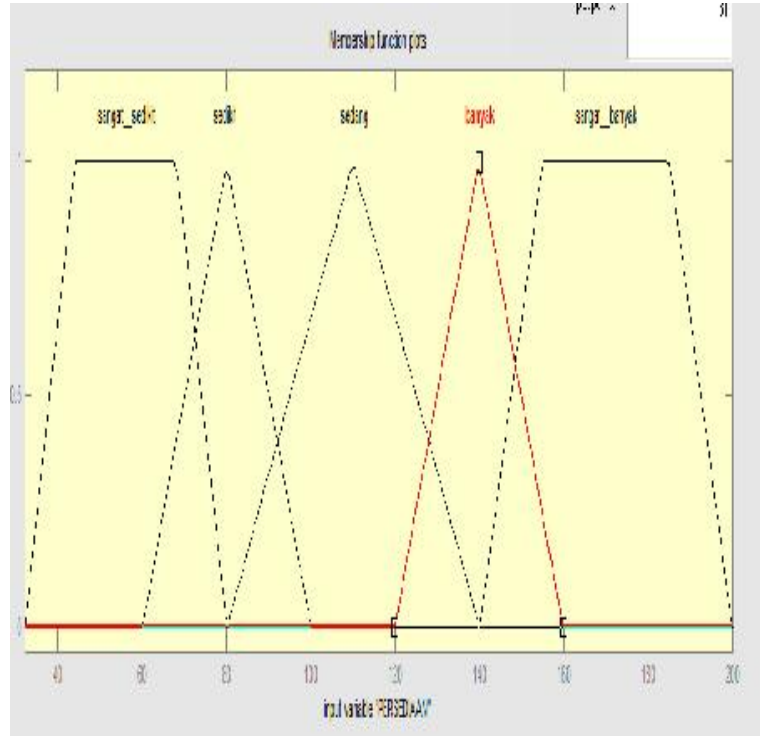

Sumber: data olahan penelitian

Gambar 7. himpunan fuzzy SangatBanyak

Pembuatan model fuzzy untuk penentuan jumlah produksi belum dikatakan baik sehingga perlu dilakukan pengujian terhadap data training sebanyak 12 tentang keakuratan dan error dari model. Pengujian model ini menggunakan tingkat keakuratan dari model.

TingkatKeakuratan $=\frac{\text { Jumlah DataBenar }}{\text { Jumlah Data Keseluruhan }} \times 100 \%$

Berdasarkan tabel diatas didapat sebagai berikut

Jumlah data benar $\quad: 11$

Jumlah data seluruhnya $\quad: 12$

Tingkat Keakuratan $=\frac{11}{12} \times 100 \%$

Tingkat Keakuratan $=91,67 \%$

Sehingga tingkat akuratan model fuzzy dengan fungsi keanggotaan segitiga yang digunakan untuk menentukan jumlah produksi pada data sebesar 91,67\% dengan error $9,37 \%$.

Dalam pengujian secara manual, penulis mengambil data bulan januari, juni dan agustus dengan output yang berbeda. Untuk pengujian selanjutnya menggunakan bantuan software MATLAB. Untuk hasil perhitungan secara manual dan MATLAB 
perbedaan hanya terletak pada hasil yang berupa bilangan desimal.

Tabel 6. Tingkat keakuratan data

\begin{tabular}{|l|l|l|l|}
\hline \multicolumn{1}{|c|}{ Data } & $\begin{array}{c}\text { Output } \\
\text { Awal }\end{array}$ & $\begin{array}{c}\text { Output } \\
\text { Asli }\end{array}$ & Keterangan \\
\hline Januari & Turun & Turun & Benar \\
\hline Februari & Turun & Turun & Benar \\
\hline Maret & Sedang & Sedang & Benar \\
\hline April & Naik & Naik & Benar \\
\hline Mei & Naik & Naik & Benar \\
\hline Juni & Naik & Naik & Benar \\
\hline Juli & Sedang & Sedang & Benar \\
\hline Agustus & Sedang & Turun & Salah \\
\hline September & Naik & Naik & Benar \\
\hline Oktober & Naik & Naik & Benar \\
\hline November & Turun & Turun & Benar \\
\hline Desember & Turun & Turun & Benar \\
\hline
\end{tabular}

Sumber: data Olahan penelitian

\section{Kesimpulan}

Penerapan logika fuzzy untuk menentukan jumlah produksi adalah defuzzifikasi yaitu penegasan kembali dari aturan yang sudah ditetapkan. Pada penelitian ini, defuzzifikasi yang digunakan adalah bisektor dengan mengambil setengah nilai domain dari fungssi keanggotaan. Tingkat keakuratan logika fuzzy dengan metode Mamdani untuk menentukan jumlah produksi berdasarkan jumlah persediaan dan jumlah permintaan pada PT OSI Electronics Batam adalah $91,67 \%$ dengan tingkat error sebesar $9,37 \%$.

\section{Saran}

Menggunakan metode yang lain dalam menentukan jumlah produksi berdasarkan jumlah persediaan dan jumlah permintaan seperti Sugeno dan Tsukamoto agar hasil yang didapatkan lebih akurat. Menambah variabel inputan logika fuzzy, seperti jenis produk, jangka waktu dan lain-lain. Menggunakan aplikasi yang lebih interaktif. Agar pengguna lebih cepat mendapatkan informasi mengenai jumlah produk yang ingin di produksi.

\section{DAFTAR PUSTAKA}

Arman Hakim Nasution Dan Yudha Prasetyawan, 2008 Perencanaan Pengendalian Dan Produksi. GRAHA ILMU, Yogyakarta

Assauri, (2008), Manejemen Produksi Dan Operasi, Fakultas Ekonomi Universitas Indonesia.

Budiharto Dan Suhartono 2014. Artificial Intellegence. C.V ANDI OFFSET.

Kusumadewi Dan Hari Purnomo, (2010), Aplikasi Logika Fuzzy Untuk Pendukung Keputusan, Graha Ilmu, Yogyakarta.

Kusumadewi, Sri. Dkk., 2006, Fuzzy MultiAttribute Decision Making (Fuzzymadm), Yogyakarta : Graha Ilmu.

Kotler El All (2008), Manajemen Pemasaran, Erlangga, Indonesia.

Kountur (2007) Metode Penelitian Untuk Penulisan Skripsi Dan Tesis/Ronny Kountur. Cetakan I Juli 2007. Buana Printing, Jakarta.

Morissan (2010) Periklanan: Komunikasi Pemasaran Terpadu. Edisi Pertama, Cetakan Ke 1. Kencana Prenada Media Grup Jakarta

Musfiqon, (2012) Panduan Lengkap Metodologi Penelitian Pendidikan. Jakarta Prestasi Pustakarya.

Naba Agus, (2009), "Belajar Cepat Fuzzy Logic Menggunakan Matlab", Yogyakarta, Andi.

Nazir,M.(2011). Metode Penelitian. Edisi Ketujuh. Ghalia Indonesia. Bogor.

Noor, (2014) Metode Penelitian Kuantitatif Dan Kualitatif Dan R\&D Cetakan Ke
20.
CV. Alfabeta Bandung

Pardede Pontas. M (2007), "Manejemen Operasi Dan Produksi- Teori, Model, Dan Kebijakan CV.ANDI OFFSET.

Suaga, 2007 FISIKA KOMPUTASI Solusi Problem Fisika Dengan Matlab. 
Cetakan Pertama Penertbit C.V ANDI Suyanto, ST Msc. 2007, Artificial OFFEST

Sugiyono, (2008), Metode Penelitian

Kuantitatif, Kualitatif Dan R\&, Intelligence,

Informatika

Alfabeta, Bandung.

Bandung. 